\title{
Non-invasive evaluation of hemodynamics in pulmonary hypertension by a Septal angle measured by computed tomography pulmonary angiography: Comparison with right-heart catheterization and association with N-terminal pro-B-type natriuretic peptide
}

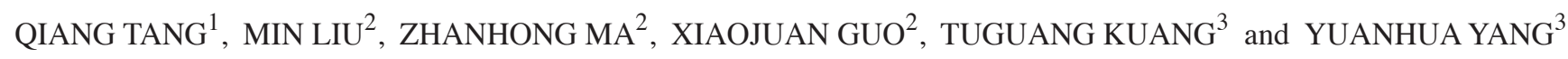 \\ ${ }^{1}$ Department of Cardiology, Shougang Hospital, Peking University, Beijing 100144; ${ }^{2}$ Department of Radiology, \\ Beijing Chaoyang Hospital, Capital Medical University; ${ }^{3}$ Respiratory Diseases Research Center, \\ Capital Medical University, Beijing 100020, P.R. China
}

Received May 21, 2013; Accepted September 12, 2013

DOI: $10.3892 /$ etm.2013.1324

\begin{abstract}
The septal angle, an angle between the interventricular septum and the line connecting the sternum midpoint and thoracic vertebral spinous process, as measured by computed tomographic pulmonary angiography (CTPA), has been observed to be increased in patients with pulmonary hypertension $(\mathrm{PH})$, but its meaning remains unclear. The aim of this study was to investigate the potential role of the septal angle in evaluating hemodynamics and its association with N-terminal pro-B-type natriuretic peptide (NT-proBNP) in patients with PH. Patients with PH $(n=106)$, including 76 with chronic thromboembolic pulmonary hypertension (CTEPH) and 30 with pulmonary artery hypertension (PAH), were retrospectively reviewed. The patients underwent CTPA prior to right-heart catheterization. The septal angle was measured on transversal CTPA images. Hemodynamic parameters were evaluated by right-heart catheterization. The level of plasma NT-proBNP was measured by enzyme-linked sandwich immunoassay. The septal angle had a moderate correlation with cardiac output $(\mathrm{CO} ; \mathrm{r}=-0.535, \mathrm{P}=0.000)$ and a high correlation with pulmonary vascular resistance (PVR; $r=0.642, \mathrm{P}=0.000)$. The mean level of NT-proBNP in $\mathrm{PH}$ was $1,716.09 \pm 1,498.30 \mathrm{pg} / \mathrm{ml}$, which correlated with the septal angle $(\mathrm{r}=0.693, \mathrm{P}=0.000)$. In a stepwise forward regression analysis, the Septal angle was entered into the final equation for predicting PVR, leading to the following equa-
\end{abstract}

Correspondence to: Dr Qiang Tang, Department of Cardiology, Shougang Hospital, Peking University, Jin Yuan Zhuang Road No. 9, Beijing 100144, P.R. China

E-mail: mikie0763@126.com

Key words: pulmonary hypertension, computer tomographic pulmonary angiography, $\mathrm{N}$-terminal pro-B-type natriuretic peptide tion: PVR $=28.256 \times$ Septal angle - 728.72. In CTEPH, the Septal angle strongly correlated with NT-proBNP ( $r=0.668$, $\mathrm{P}=0.000)$ and PVR $(\mathrm{r}=0.676, \mathrm{P}=0.000)$. In PAH, the Septal angle strongly correlated with NT-proBNP $(\mathrm{r}=0.616, \mathrm{P}=0.003)$ and PVR ( $\mathrm{r}=0.623, \mathrm{P}=0.000)$. The CTPA-derived Septal angle is a superior predictor for evaluating and monitoring the level of NT-proBNP and PVR in patients with PH.

\section{Introduction}

Pulmonary hypertension (PH) is defined as a mean pulmonary arterial pressure (mPAP) $>25 \mathrm{mmHg}$ at rest or as pulmonary vascular resistance (PVR) $>3$ Wood units (1). PH comprises apparently heterogeneous conditions that may have comparable clinical and hemodynamic characteristics, and is characterized by progressive obliteration of pulmonary arterioles, leading to the increase of PVR, right-heart failure and mortality. Over the past years, numerous advances in researching and understanding the pulmonary vascular biology have been revealed. The evaluation of the severity of $\mathrm{PH}$ is important in the diagnostic process and therapeutic decision-making.

The clinical history, physical examination and biochemical markers of a patient may suggest $\mathrm{PH}$ and right ventricular dysfunction. Currently, right-heart catheterization enables the direct measurement of hemodynamics and remains the reference standard for the evaluation of $\mathrm{PH}(2,3)$, and it is yet to be replaced by another approach. However, invasiveness and surgical skill requirements are the major weaknesses of heart catheterization. Echocardiography is able to evaluate pulmonary pressure and right ventricular function in a noninvasive manner. However, occasionally echocardiography underestimates the mild increased pulmonary pressure and is unable to supply information concerning emboli of the distal pulmonary artery. B-type natriuretic peptide (BNP) and its prohormone $\mathrm{N}$-terminal pro-B-type natriuretic peptide (NT-proBNP) are peptides released from the myocardium, and studies suggest an abnormal increase in the NT-proBNP response to ventricular wall stress and dysfunction. In patients with $\mathrm{PH}$, increasing 
evidence suggests that NT-proBNP is a useful marker for right ventricular dysfunction and predicts the outcome of PH (4-7).

Recently, computed tomographic pulmonary angiography (CTPA) has been used to provide much more important information, including establishing the diagnosis, defining its cause, quantifying its hemodynamic parameters, and aiding therapeutic planning and monitoring in pulmonary vascular disease. CTPA is already established as a first line test in acute pulmonary embolism (APE) (8-11). The retrospective electrocardiography (ECG)-gating technique in CT angiography now enables more comprehensive evaluation of cardiac vessels and function. Previously, studies have reported that certain cardiovascular parameters from CTPA are able to assess the extent of pulmonary artery obstruction and right ventricular function (12-15). An angle in transversal images of CTPA between the connecting line from the midpoint of the sternum to the thoracic vertebral spinous process and interventricular septum, named as Septal angle by us firstly, was reported to be correlated with PVR in patients with chronic thromboembolic pulmonary hypertension (CTEPH) $(16,17)$. For further clarification of the role of the Septal angle in assessment severity of $\mathrm{PH}$ and its correlation with right ventricular function, we performed a retrospective study to explore the association between the CTPA-derived Septal angle and hemodynamics, and the level of NT-proBNP in patients with PH.

\section{Materials and methods}

Patients. Between January 2007 and March 2011, 106 consecutive patients with confirmed $\mathrm{PH}$ including $76 \mathrm{CTEPH}$ patients and 30 pulmonary artery hypertension (PAH) patients in Peking University Shougang Hospital and Chaoyang Hospital of Capital Medical University (Beijing, China) were included in this retrospective study. PH was diagnosed according to the European Society of Cardiology (ESC)/European Respiratory Society (ERS) Guidelines (2). The medical record of each patient was reviewed by one doctor. Patients who underwent CTPA, right-heart catheterization and NT-proBNP tests were included. Exclusion criteria included the following: i) patients that were not subject to CTPA or CTPA with inferior image quality; ii) patients without right-heart catheterization; and iii) patients without NT-proBNP testing. The control group was composed of 106 age- and gender-matched control subjects without PH and pulmonary embolism. The study protocol was approved by the institutional ethics review committees of Peking University and Captial Medical University. All patients provided written informed consent.

CTPA acquisition and image analysis. A 64-row multidetector CT scanner (LightSpeed VCT; GE Healthcare, Milwaukee, WI, USA) using the retrospective ECG-gated mode was used for CTPA scanning. The whole chest was scanned from the lung apex to the diaphragm with a single breath-hold. Scan parameters included the following: current of 300-550 mA modulated by personal body mass index (BMI) dose; tube voltage of $100-140 \mathrm{kV}$ and collimation of $0.625 \mathrm{~mm}$, gantry rotation time of $0.8 \mathrm{sec}$, table speed of $39.37 \mathrm{~mm} / \mathrm{sec}$ and reconstruction increment of $1 \mathrm{~mm}$. A mechanical injector was used for intravenous bolus injection of iopromide $(370 \mathrm{mg} / \mathrm{ml}$, Ultravist; Bayer Schering Pharma, Berlin, Germany) at a flow
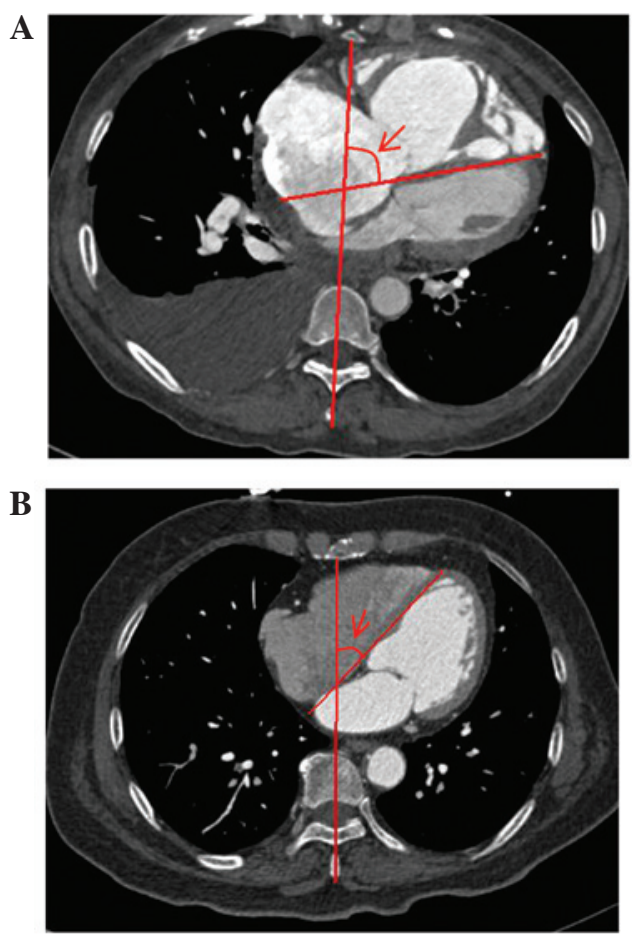

Figure 1. Septal angle measured on transverse images of computed tomographic pulmonary angiography (CTPA) in (A) a patient with CTEPH and (B) a normal patient. CTEPH, chronic thromboembolic pulmonary hypertension.

rate of $4.5-5.0 \mathrm{ml} / \mathrm{sec}$. The automatic bolus-tracking technique had the region of interest positioned at the level of the main pulmonary artery with a pre-defined threshold of $100 \mathrm{HU}$, and a fixed delay of $5 \mathrm{sec}$ was employed for data acquisition.

Images were transferred to the electronic picture archiving and communication systems (GE Centricity 3000 RA1000; GE Healthcare) and reviewed by two radiologists together blinded to clinical information. Fig. 1 shows that the Septal angle was measured in diastole in the transverse CTPA image. According our previously described methods (15-17), other parameters including the diameter of main pulmonary artery (MPAd), diameter of ascending aorta (AAd), transverse diameter of right atrium (RAd), transverse diameter of right ventricle and left ventricle ( RVd and LVd), interventricular septal thickness (IVST), and right and left ventricular area (RVa and LVa) were all measured on the transverse images. The ratio of MPAa and AAd (MPAa/AAd), the ratio of $\mathrm{RVd}$ and $\mathrm{LVd}(\mathrm{RVd} / \mathrm{LVd})$ and the ratio of RVa and LVa (RVa/LVa) were measured.

Right-heart catheterization. Right-heart catheterization was used at 3-5 days after CTPA. By using the Seldinger technique, an 8F Swan-Ganz catheter (Baxter Healthcare, Irvine, CA, USA) was introduced through a right internal jugular vein and positioned under fluoroscopic guidance in a pulmonary artery. After a 10-min rest for stabilization, hemodynamic parameters including right atrial pressure (RAP), pulmonary arterial systolic pressure (sPAP), pulmonary artery diastolic pressure (dPAP), pulmonary capillary wedge pressure (PCWP) and cardiac output $(\mathrm{CO})$ were obtained at end-expiration, then the mPAP and PVR were calculated. The PVR was calculated as 
Table I. Clinical and hemodynamic characteristics of patients with $\mathrm{PH}$

\begin{tabular}{|c|c|}
\hline Characteristics & Values \\
\hline \multicolumn{2}{|c|}{ Baseline parameters $($ mean $\pm \mathrm{SD})$} \\
\hline Age (years) & $50.86 \pm 13.40$ \\
\hline Gender (male/female) & $53 / 53$ \\
\hline Body mass index $\left(\mathrm{kg} / \mathrm{m}^{2}\right)$ & $23.44 \pm 3.12$ \\
\hline Body surface area $\left(\mathrm{m}^{2}\right)$ & $1.73 \pm 0.18$ \\
\hline NT-proBNP $(\mathrm{pg} / \mathrm{ml})$ & $1716.09 \pm 1498.30$ \\
\hline Septal angle (degree) & $65.32 \pm 11.93$ \\
\hline \multicolumn{2}{|c|}{ Clinical classification of $\mathrm{PH}(\mathrm{n})$} \\
\hline СТEPH & 76 \\
\hline Idiopathic PAH & 24 \\
\hline \multicolumn{2}{|c|}{ Connective tissue diseases associated } \\
\hline PAH & 2 \\
\hline Heritable PAH & 2 \\
\hline $\begin{array}{l}\text { PAH associated with cong } \\
\text { disease }\end{array}$ & 2 \\
\hline \multicolumn{2}{|l|}{ Class of PAP (n) } \\
\hline Mild (25-39 mmHg) & 17 \\
\hline Moderate $(40-69 \mathrm{mmHg})$ & 70 \\
\hline Severe $(\geq 70 \mathrm{mmHg})$ & 19 \\
\hline \multicolumn{2}{|l|}{ NYHA classification (n) } \\
\hline $\mathrm{I}$ & 6 \\
\hline II & 44 \\
\hline III & 46 \\
\hline IV & 10 \\
\hline \multicolumn{2}{|l|}{ Hemodynamics (mean \pm SD) } \\
\hline RAP (mmHg) & $7.78 \pm 6.11$ \\
\hline sPAP (mmHg) & $86.14 \pm 23.70$ \\
\hline dPAP (mmHg) & $33.11 \pm 12.63$ \\
\hline mPAP (mmHg) & $51.58 \pm 15.65$ \\
\hline $\mathrm{CO}(1 / \mathrm{min})$ & $3.47 \pm 1.36$ \\
\hline PCWP $(\mathrm{mmHg})$ & $9.13 \pm 3.72$ \\
\hline PVR (dynes.sec.mm5) & $1121.09 \pm 582.37$ \\
\hline
\end{tabular}

$\mathrm{PH}$, pulmonary hypertension; NT-proBNP, N-terminal pro-B-type natriuretic peptide; CTEPH, chronic thromboembolic pulmonary hypertension; PAH, pulmonary arterial hypotension; PAP, pulmonary artery pressure; NYHA, New York Heart Association; RAP, right atrial pressure; sPAP, pulmonary artery systolic pressure; dPAP, pulmonary artery diastolic pressure; mPAP, mean pulmonary artery pressure; CO, cardiac output; PCWP, pulmonary capillary wedge pressure; PVR, pulmonary vascular resistance.

described by Tramarin et al (18). CO was determined by the thermodilution method (19), with the exception of two cases of congenital heart disease-associated PAH where the Fick method (20) was used to determine $\mathrm{CO}$, as the mean of three consecutive measurements not varying by $>10 \%$.

Plasma level of NT-proBNP. When we performed pulmonary angiography and right-heart catheterization, a blood sample was drawn from the pulmonary artery and immediately

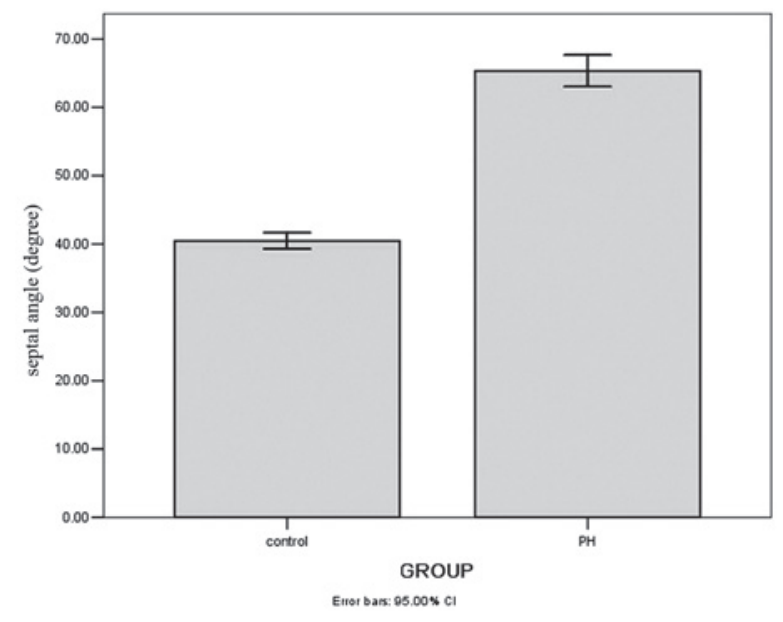

Figure 2. Comparison of Septal angle in pulmonary hypertension $(\mathrm{PH})$ and the control group. CI, confidence interval.

transferred into ethylenediaminetetraacetic acid-glass tubes and centrifuged at 3,000 rpm for $15 \mathrm{~min}$ at $4^{\circ} \mathrm{C}$. The level of NT-proBNP was determined by an enzyme-linked sandwich immunoassay (Elecsys NT-proBNP; Roche Diagnostics, Indianapolis, IN, USA).

Statistical analysis. All data are expressed as mean \pm standard deviation (SD), unless otherwise specified. All analyses were performed with a statistical package (SPSS 13; SPSS, Inc., Chicago, IL, USA). A Mann-Whitney U test was used to compare the Septal angle in the $\mathrm{PH}$ and normal control groups. The association of Septal angle with clinical parameters was calculated by univariate analysis. The correlations of Septal angle with NT-proBNP and hemodynamics were analyzed with the Spearman's correlation. Stepwise linear regression analysis was used to evaluate the predictive power of independent CTPA variables for PVR. The receiver-operating characteristic (ROC) method was used to analyze the cut-off value of Septal angle and NT-proBNP for assessing PVR $\geq 1,000$ (dyn.sec/ $\mathrm{cm}^{5}$ ). All P-values were for 2-sided tests. $\mathrm{P}<0.05$ was considered to indicate a statistically significant result.

\section{Results}

Characteristics of the study population. The clinical characteristics of the PH group (age, 14-84 years; median, 51 years) are shown in Table I. The average Septal angle in the PH group was $65.33 \pm 11.93^{\circ}$ with a range of $40.00-97.30^{\circ}$ (Fig. 1A) and all patients had clear signs of PAH as revealed in Table I. In the control group, the average Septal angle was $40.47 \pm 6.11^{\circ}$ with range of $25.50-54.50^{\circ}$ and a median of $40.25^{\circ}$ (Fig. 1B). As shown in Fig. 2, the Septal angle in the PH group was significantly higher than that in the control group (Mann-Whitney $\mathrm{U}$ test, $\mathrm{U}=280.5, \mathrm{P}=0.000$ ).

No correlation was observed between the Septal angle and age $(\mathrm{r}=0.101, \mathrm{P}=0.307), \mathrm{BMI}(\mathrm{r}=-0.120, \mathrm{P}=0.221)$ or body surface area $(\mathrm{r}=-0.150, \mathrm{P}=0.127)$. The Septal angle in males and females was $65.86 \pm 13.38$ and $64.78 \pm 10.36^{\circ}$, respectively, which has no significant difference (Mann-Whitney U test; 
Table II. Comparison of Septal angle and hemodynamics in CTEPH and PAH.

\begin{tabular}{|c|c|c|c|c|}
\hline Parameters & CTEPH & PAH & $\mathrm{U}^{\mathrm{a}}$ & P-value \\
\hline Septal angle $\left({ }^{\circ}\right)$ & $65.76 \pm 12.25$ & $64.19 \pm 11.19$ & 1053.5 & 0.728 \\
\hline RAP (mmHg) & $8.04 \pm 5.90$ & $7.13 \pm 6.68$ & 993.5 & 0.303 \\
\hline sPAP (mmHg) & $85.62 \pm 20.61$ & $91.00 \pm 30.24$ & 1030.0 & 0.440 \\
\hline dPAP (mmHg) & $31.71 \pm 9.97$ & $36.67 \pm 17.40$ & 921.0 & 0.124 \\
\hline mPAP (mmHg) & $50.00 \pm 12.73$ & $55.56 \pm 21.08$ & 939.0 & 0.158 \\
\hline PCWP (mmHg) & $8.79 \pm 2.97$ & $9.96 \pm 5.12$ & 1054.0 & 0.612 \\
\hline $\mathrm{CO}(1 / \mathrm{min})$ & $3.42 \pm 1.22$ & $3.62 \pm 1.36$ & 1033.0 & 0.453 \\
\hline PVR (dynes.sec.mm ${ }^{-5}$ ) & $1113.66 \pm 564.96$ & $1139.93 \pm 673.60$ & 1106.0 & 0.812 \\
\hline
\end{tabular}

${ }^{a}$ Mann-Whitney U test. CTEPH, chronic thromboembolic pulmonary hypertension; PAH, pulmonary arterial hypertension; RAP, right atrial pressure; sPAP, pulmonary artery systolic pressure; dPAP, pulmonary artery diastolic pressure; mPAP, mean pulmonary artery pressure; PCWP, pulmonary capillary wedge pressure; $\mathrm{CO}$, cardiac output; PVR, pulmonary vascular resistance.

A

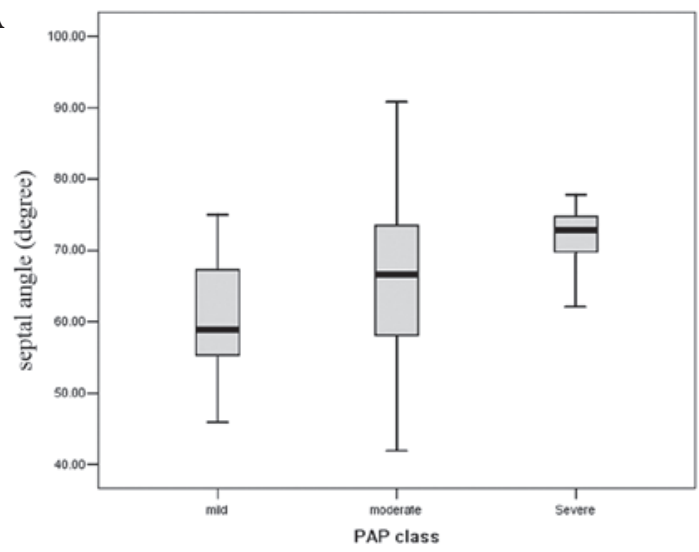

B

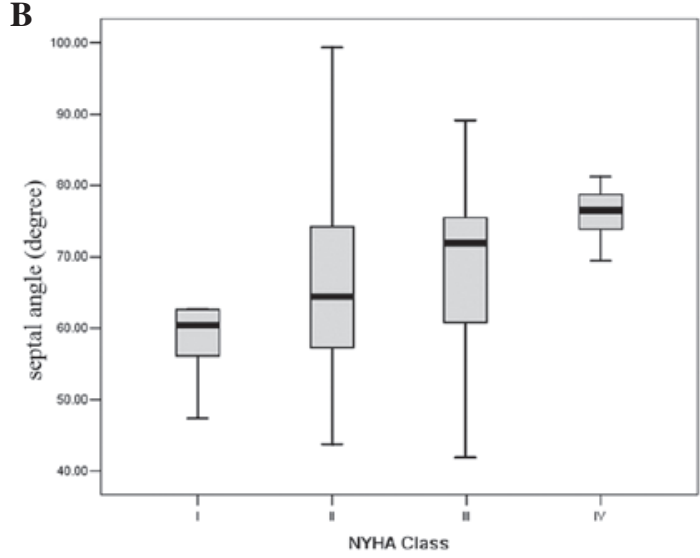

Figure 3. Correlation of Septal angle with (A) class of pulmonary artery pressure (PAP) and (B) New York Heart Association (NYHA) classification.

$\mathrm{U}=1370.0, \mathrm{P}=0.959)$. The Septal angle in CTEPH and PAH groups was $65.76 \pm 12.25$ and $64.19 \pm 11.19^{\circ}$, respectively, and there was no difference in Septal angle between the two groups (Mann-Whitney U test; $\mathrm{U}=1053.5, \mathrm{P}=0.728$ ). The Septal angle was weakly correlated with the class of PAP $(r=0.278$, $\mathrm{P}=0.004$; Fig. 3A) and New York Heart Association (NYHA) classification ( $r=0.255, P=0.009$; Fig. $3 \mathrm{~B})$. No difference in hemodynamic parameters was identified between CTEPH and PAH, as shown in Table II.

Correlation of the Septal angle with hemodynamics and NT-proBNP in PH. Correlations between the Septal angle and the hemodynamic parameters evaluated by right-heart catheterization (Table III) showed that the Septal angle strongly correlated with PVR $(r=0.642, \mathrm{P}=0.000)$, moderately correlated with $\mathrm{CO}(\mathrm{r}=-0.535, \mathrm{P}=0.000)$ and cardiac index $(\mathrm{CI} ; \mathrm{r}=-0.534, \mathrm{P}=0.000)$ and weakly correlated with RAP $(\mathrm{r}=0.255, \mathrm{P}=0.009), \mathrm{PPAP}(\mathrm{r}=0.258, \mathrm{P}=0.008), \mathrm{dPAP}(\mathrm{r}=0.275$, $\mathrm{P}=0.005)$ and mPAP $(\mathrm{r}=0.294, \mathrm{P}=0.002)$, but did not correlate with pulse oxygen saturation $\left(\mathrm{SPO}_{2} ; \mathrm{r}=0.015, \mathrm{P}=0.885\right)$ or PCWP ( $\mathrm{r}=-0.025, \mathrm{P}=0.803)$. Correlations between the CTPA variables and PVR (Table IV) suggest that PVR strongly correlated with the Septal angle and moderately correlated with $\mathrm{RVa} / \mathrm{LVa}(\mathrm{r}=0.537, \mathrm{P}=0.000)$ and $\mathrm{RVd} / \mathrm{LVd}(\mathrm{r}=0.479$, $\mathrm{P}=0.000)$.

When all CTPA variables were analyzed in a stepwise forward regression analysis, the Septal angle and $\mathrm{RVa} / \mathrm{LVa}$ were entered into the final equation for predicting PVR, as shown in Table V, leading to the following two equations: i) PVR $=28.256$ x Septal angle -728.72 ; and ii) $\mathrm{PVR}=23.005 \times$ Septal angle $+207.992 \times \mathrm{RVa} / \mathrm{LVa}-718.69$. The level of NT-proBNP was $1,716.09 \pm 1,498.30 \mathrm{pg} / \mathrm{ml}$ with a range of $19.79-5,909.00 \mathrm{pg} / \mathrm{ml}$. Correlations between CTPA variables and NT-proBNP (Fig. 4) demonstrated that NT-proBNP strongly correlated with the Septal angle $(r=0.693$, $\mathrm{P}=0.000)$ and moderately correlated with $\mathrm{RVa} / \mathrm{LVa}(\mathrm{r}=0.520$, $\mathrm{P}=0.000)$, RAd $(\mathrm{r}=0.447, \mathrm{P}=0.000)$ and $\mathrm{RVd} / \mathrm{LVd}(\mathrm{r}=0.395$, $\mathrm{P}=0.000)$.

Association of Septal angle and hemodynamics, NT-proBNP in CTEPH. In the CTEPH group, Spearman's correlations between the Septal angle and hemodynamic data evaluated by right-heart catheterization (Table III) showed that the Septal angle had a strong correlation with PVR ( $\mathrm{r}=0.676, \mathrm{P}=0.000)$, a moderate correlation with $\mathrm{CO}(\mathrm{r}=-0.586, \mathrm{P}=0.000)$ and $\mathrm{CI}$ $(\mathrm{r}=-0.595, \mathrm{P}=0.000)$, a weak correlation with RAP $(\mathrm{r}=0.301$, 
Table III. Correlations between Septal angle and hemodynamic parameters in PH and its subgroups.

\begin{tabular}{lccc}
\hline & \multicolumn{3}{c}{ Spearman's correlation analysis (r, P-value) } \\
\cline { 2 - 4 } Hemodynamics & $\mathrm{PH}(\mathrm{n}=106)$ & CTEPH $(\mathrm{n}=76)$ & $\mathrm{PAH}(\mathrm{n}=30)$ \\
\hline RAP & $0.255,0.009$ & $0.301,0.008$ & $0.105,0.587$ \\
SPAP & $0.258,0.008$ & $0.209,0.070$ & $0.304,0.030$ \\
dPAP & $0.275,0.005$ & $0.251,0.029$ & $0.387,0.038$ \\
mPAP & $0.294,0.002$ & $0.256,0.026$ & $0.343,0.016$ \\
PCWP & $-0.025,0.803$ & $-0.053,0.655$ & $-0.221,0.249$ \\
CO & $-0.535,0.000$ & $-0.586,0.000$ & $-0.553,0.000$ \\
CI & $-0.534,0.000$ & $-0.595,0.000$ & $-0.561,0.000$ \\
PVR & $0.642,0.000$ & $0.676,0.000$ & $0.623,0.000$ \\
SPO & $0.015,0.885$ & $0.022,0.853$ & $0.119,0.540$ \\
\hline
\end{tabular}

PH, pulmonary hypertension; CTEPH, chronic thromboembolic pulmonary hypertension; PAH, pulmonary arterial hypertension; RAP, right atrium pressure; SPAP, pulmonary artery systolic pressure; dPAP, pulmonary artery diastolic pressure; mPAP, mean pulmonary artery pressure; PCWP, pulmonary capillary wedge pressure; $\mathrm{CO}$, cardiac output; $\mathrm{CI}$, cardiac index; PVR, pulmonary vascular resistance; $\mathrm{SPO}_{2}$, pulse oxygen saturation.

A

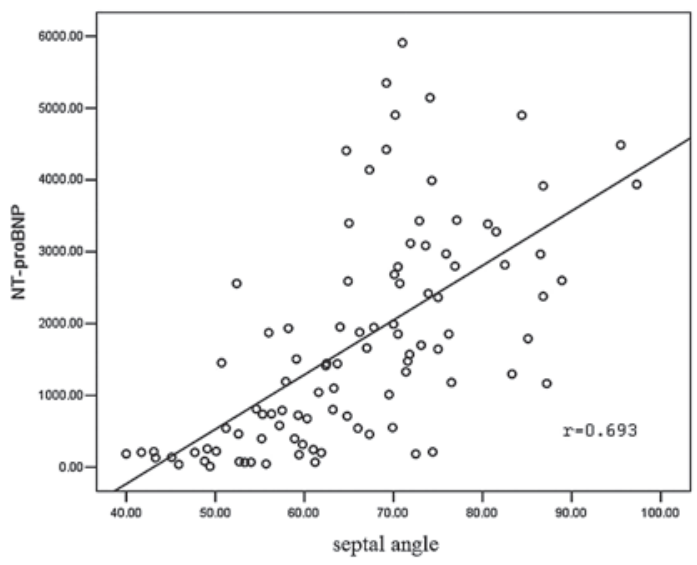

C

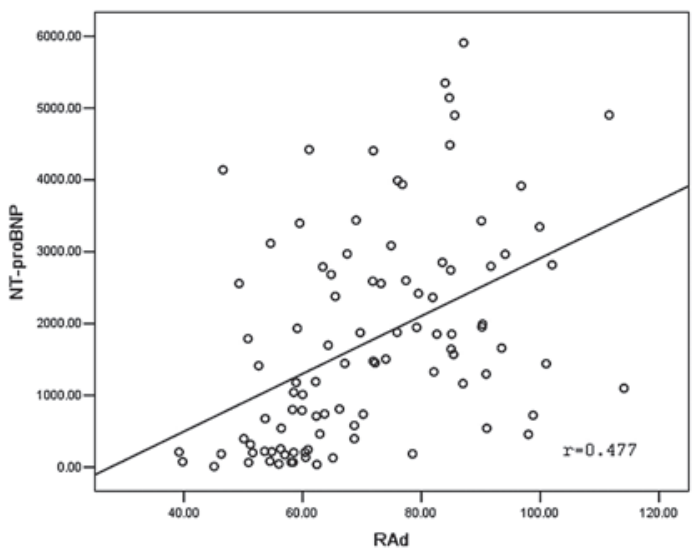

B

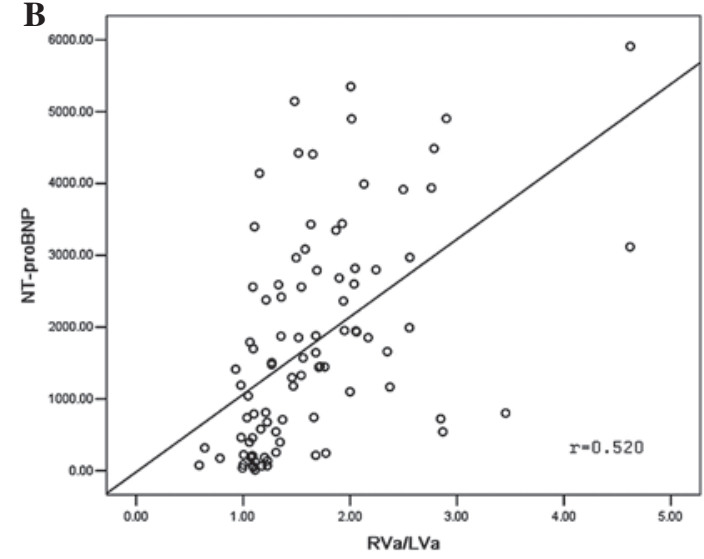

D

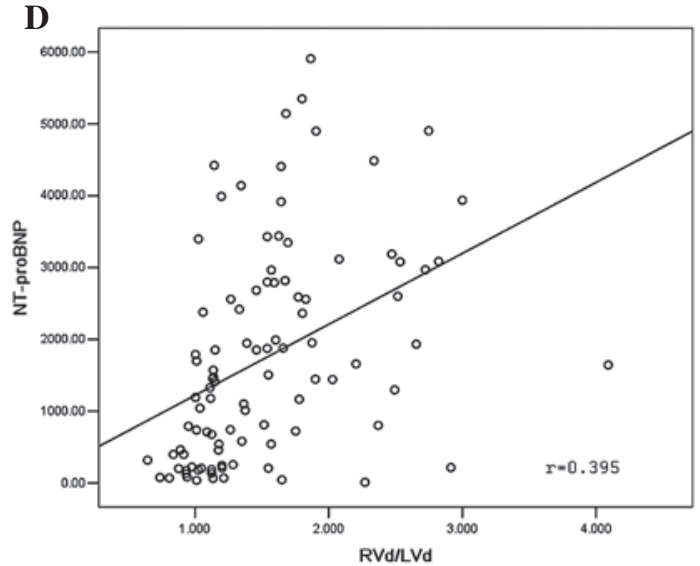

Figure 4. Correlation of computed tomographic pulmonary angiography (CTPA) variables with the level of NT-proBNP. (A) Correlation between Septal angle and NT-proBNP ( $\mathrm{r}=0693$, $\mathrm{P}=0.000)$; (B) correlation between RVa/LVa and NT-proBNP ( $\mathrm{r}=0.520, \mathrm{P}=0.000)$; (C) correlation between RAd and NT-proBNP $(\mathrm{r}=0.477, \mathrm{P}=0.000)$; (D) correlation between $\mathrm{RVd} / \mathrm{LVd}$ and NT-proBNP $(\mathrm{r}=0.395, \mathrm{P}=0.000)$. NT-proBNP, N-terminal pro-B-type natriuretic peptide; $\mathrm{RVa}$, right ventricular area; LVa, left ventricular area; RAd, transverse diameter of right atrium; RVd, transverse diameter of right ventricle; LVd, transverse diameter of left ventricle. 
Table IV. Correlations between CTPA variables and PVR in patients with $\mathrm{PH}$.

\begin{tabular}{lcc}
\hline CTPA parameters & Correlation coefficient $^{\mathrm{a}}$ & P-value \\
\hline Septal angle & 0.642 & 0.000 \\
RVa/LVa & 0.537 & 0.000 \\
RVd/LVd & 0.479 & 0.000 \\
RAd & 0.321 & 0.010 \\
RVa & 0.248 & 0.013 \\
RVd & 0.240 & 0.016 \\
MPAd/AAd & 0.217 & 0.027 \\
IVST & -0.139 & 0.163 \\
\hline
\end{tabular}

aSpearman's correlation analysis. CTPA, computed tomography pulmonary angiography; PVR, pulmonary vascular resistance; $\mathrm{PH}$, pulmonary hypertension; $\mathrm{RVa} / \mathrm{LVa}$, ratio of right ventricular area to left ventricular area; $\mathrm{RVd} / \mathrm{LVd}$, ratio of transverse diameters between right ventricle to left ventricle; RAd, transverse diameter of right atrium; RVa, right ventricular area; RVd, transverse diameter of right ventricle; MPAd/AAd, ratio of the diameter of main pulmonary artery to the diameter of the ascending aorta; IVST, interventricular septal thickness.

$1,809.52 \pm 1,532.16 \mathrm{pg} / \mathrm{ml}$ with a range of $19.79-5,909.00 \mathrm{pg} / \mathrm{ml}$, and the Septal angle had a strong correlation with NT-proBNP $(\mathrm{r}=0.668, \mathrm{P}=0.000)$.

Correlation of Septal angle and hemodynamics, NT-proBNP in PAH. In the PAH group, Spearman's correlations between Septal angle and hemodynamic data evaluated by right-heart catheterization (Table III) showed that the Septal angle strongly correlated with PVR ( $\mathrm{r}=0.623, \mathrm{P}=0.000)$, moderately correlated with $\mathrm{CO}(\mathrm{r}=-0.553, \mathrm{P}=0.000)$ and $\mathrm{CI}(\mathrm{r}=-0.561$, $\mathrm{P}=0.000)$, weakly correlated with $\mathrm{sPAP}(\mathrm{r}=0.304, \mathrm{P}=0.030)$, dPAP ( $\mathrm{r}=0.387, \mathrm{P}=0.038)$ and mPAP $(\mathrm{r}=0.343, \mathrm{P}=0.016)$, but did not correlate with $\mathrm{SPO}_{2}(\mathrm{r}=0.119, \mathrm{P}=0.540), \mathrm{RAP}(\mathrm{r}=0.105$, $\mathrm{P}=0.587)$ or $\mathrm{PCWP}(\mathrm{r}=-0.221, \mathrm{P}=0.249)$. The level of plasma NT-proBNP in PAH was $1,582.43 \pm 1,387.30 \mathrm{pg} / \mathrm{ml}$ with a range of $83.10-4,453.00 \mathrm{pg} / \mathrm{ml}$ and the Septal angle had a strong correlation with the level of NT-proBNP $(r=0.616, \mathrm{P}=0.003)$.

ROC analysis. In PH, as shown in ROC analysis (Fig. 5), a Septal angle cut-off point of $\geq 67.55^{\circ}$ had a $77.1 \%$ sensitivity and a $87.5 \%$ specificity for predicting PVR $\geq 1,000$ (dynes.sec. $\mathrm{mm}^{-5}$ ); its area under the curve (AUC) was $0.850 \pm 0.040$. An NT-proBNP cut-off point $\geq 1,443 \mathrm{pg} / \mathrm{ml}$ had a $75.0 \%$ sensitivity and a $75.0 \%$ specificity for predicting PVR $\geq 1,000$ (dynes.sec. $\mathrm{mm}^{-5}$ ); its AUC was $0.808 \pm 0.046$, comparable or even inferior to the AUC of the Septal angle for predicting PVR $\geq 1,000$ (dynes.sec. $\mathrm{mm}^{-5}$ ).

In the CTEPH group, ROC analysis (Fig. 6) demonstrated that a Septal angle cut-off point of $\geq 67.55^{\circ}$ had a $75.0 \%$ sensitivity and a $84.6 \%$ specificity for predicting PVR $\geq 1,000$ (dynes.sec. $\mathrm{mm}^{-5}$ ), and its AUC was $0.827 \pm 0.050$. An NT-proBNP cut-off point of $\geq 1,443 \mathrm{pg} / \mathrm{ml}$ had a $83.3 \%$ sensitivity and a $71.8 \%$ specificity for predicting PVR $\geq 1,000$ (dynes.sec. $\mathrm{mm}^{-5}$ ), and its AUC was $0.822 \pm 0.049$, comparable to the AUC of the Septal angle for predicting PVR $\geq 1,000$ (dynes.sec. $\mathrm{mm}^{-5}$ ).

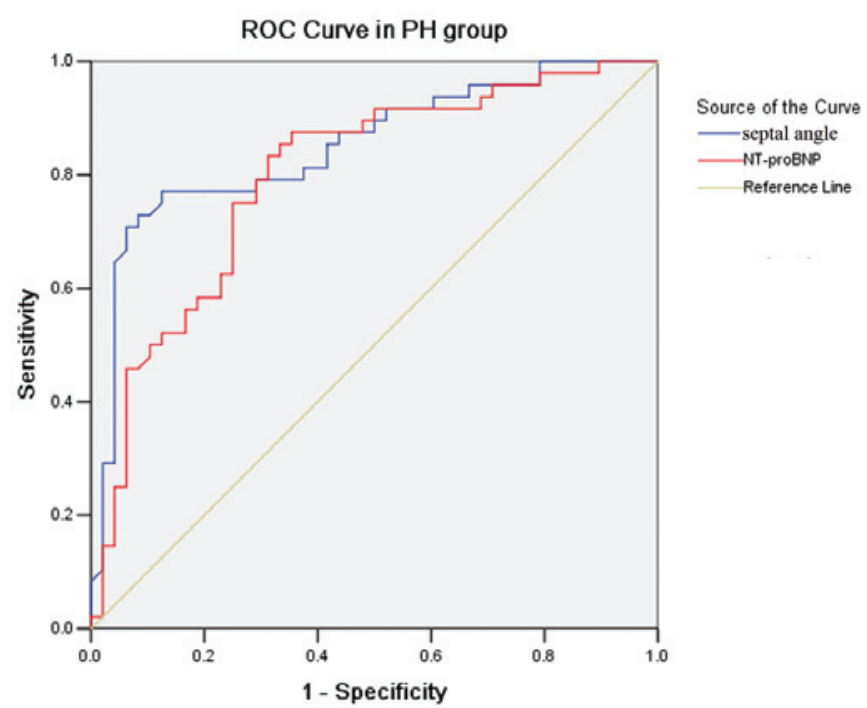

Figure 5. Comparison of receiver-operating characteristic (ROC) curves of Septal angle and NT-proBNP in patients with pulmonary hypertension $(\mathrm{PH})$. The area under the curve (AUC) was 0.850 (95\% confidence interval, $0.770-0.929, \mathrm{P}=0.000)$ for Septal angle and 0.808 (95\% confidence interval, 0.717-0.905, $\mathrm{P}=0.000$ ) for NT-proBNP. NT-proBNP, N-terminal pro-B-type natriuretic peptide.

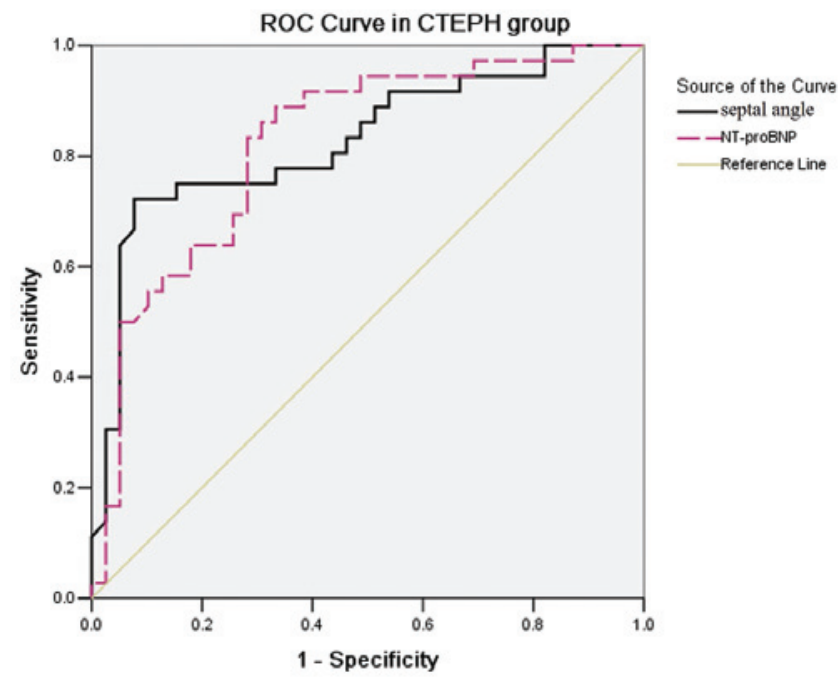

Figure 6. Receiver-operating characteristic (ROC) curves of Septal angle and NT-proBNP predicting pulmonary vascular resistance $(\mathrm{PVR}) \geq 1,000$ (dyn.sec/ $\mathrm{cm}^{5}$ ) in patients with chronic thromboembolic pulmonary hypertension (CTEPH). The area under the curve (AUC) was 0.827 (95\% confidence interval, $0.730-0.924, \mathrm{P}=0.000)$ for Septal angle and 0.822 (95\% confidence interval, 0.725-0.918, $\mathrm{P}=0.00$ ) for NT-pro-BNP. NT-proBNP, N-terminal proB-type natriuretic peptide.

\section{Discussion}

Our prior studies suggest that CTPA clearly describes the obstructed pulmonary artery (15) and the cardiovascular parameters of CTPA may be used to evaluate the hemodynamics in CTEPH $(16,17)$. In the present study, we analyzed the correlation of Septal angle with the hemodynamics and the level of NT-proBNP in patients with PH and its two subgroups, 
Table V. Stepwise linear regression analysis of the relation between CTPA predictions and PVR.

\begin{tabular}{lccrrrr}
\hline Model $^{\mathrm{a}}$ & $\mathrm{R}$ & Predictors $^{\mathrm{b}}$ & $\mathrm{F}-\mathrm{value}$ & $\mathrm{B}$ & $\mathrm{t}$ & Significance $^{2}$ \\
\hline Model 1 & \multirow{2}{*}{0.588} & Septal angle & 52.351 & 28.256 & 7.235 & 0.000 \\
& & (constant) & & -728.740 & -2.811 & 0.000 \\
Model 2 & \multirow{2}{*}{0.631} & Septal angle & 32.363 & 23.005 & 5.504 & 0.000 \\
& & RVa/LVa & & 207.992 & 2.905 & 0.005 \\
& & (constant) & & -718.690 & -2.784 & 0.005 \\
\hline
\end{tabular}

aDependent variable: PVR; ${ }^{b}$ predictors in the model of ratio of right ventricular area to left ventricular area (RVa/LVa). CTPA, computed tomography pulmonary angiography; PVR, pulmonary vascular resistance; B, coefficient.

CTEPH and PAH. We demonstrated that: i) the Septal angle in $\mathrm{PH}$ patients is larger than that in the normal control, but weakly correlated with PAP. ii) the Septal angle is strongly correlated with PVR and NT-proBNP in PH and its two subgroups (CTEPH and PAH). iii) In CTEPH, a Septal angle cut-off value of 67.55 has a sensitivity of $77 \%$ and a specificity of $81 \%$ in predicting PVR $\geq 1,000$ (dyn.sec/ $\mathrm{cm}^{5}$ ), comparable to the level of NT-proBNP. iv) In PH, a Septal angle cut-off value of $67.55^{\circ}$ is comparable to the NT-proBNP cut-off value of $1,443 \mathrm{pg} / \mathrm{ml}$ in predicting PVR $\geq 1,000\left(\right.$ dyn.sec $\left./ \mathrm{cm}^{5}\right)$.

Septal angle is a CTPA-derived parameter that is an angle between the connection line from the midpoint of the sternum to thoracic vertebral spinous process and interventricular septum. This angle represents the balance of left and right ventricular load. Our results revealed that in the control group, the right ventricular (RV) pressure is lower than the left ventricular (LV) pressure; the mean Septal angle is $40.47^{\circ}$ (range 25.50-54.50 ) and the Septal angle in the $\mathrm{PH}$ group is significantly higher than that in the control group, but there is no difference in the CTEPH and PAH groups. This suggests the increased Septal angle is a predictor of $\mathrm{PH}$, and is not affected by the etiology of PH. We observed that Septal angle only weakly increased with the extent of PAP. This suggests PAP does not directly impact on the Septal angle. Although the Septal angle in PH was not affected by age, BMI or body surface area, there was an overlap of Septal angle between PH and the control group, so the normal value of the Septal angle requires validation in a large population. During the progress of $\mathrm{PH}$, the marked increase in PVR limits the rate at which the right ventricle is able to pump blood through the lungs, leading to RV overload, hypertrophy and dilatation (21-24). $\mathrm{RV}$ overload causes flattening and leftward displacement of the interventricular septum, and cardiac clockwise rotation, so we suggest that the enlarged septal angle is a sign of the right ventricular overload in patients with PH $(23,24)$.

Resting hemodynamics measured by right-heart catheterization may assess the severity and predict the prognosis of PH $(2,3,25)$. PVR is one of the most important parameters in this, since the increased PVR leads to right ventricular overload and dysfunction. Previous studies demonstrated that parameters such as $\mathrm{RVd} / \mathrm{LVd}$ correlated with hemodynamic data $(16,17)$. There is no data available so far associating the Septal angle with the resting hemodynamics of patients with PH. We observed a strong correlation of Septal angle and a moderate correlation of $\mathrm{RVd} / \mathrm{LVd}$ with PVR in $\mathrm{PH}$ patients.
By a stepwise regression analysis, the Septal angle was entered into a final equation for predicting PVR. This suggests the Septal angle may be a superior indicator for evaluating PVR than $\mathrm{RVd} / \mathrm{LVd}$. NT-proBNP is released from myocytes and may be used as an indicator of the severity of PH (26). The very high serum NT-proBNP concentrations observed in the patients with $\mathrm{PH}$ who were studied most likely result from an increased RV wall stretch and marked hypertrophy of the RV walls (27-29). Our data indicated that the Septal angle strongly correlated with NT-proBNP and demonstrated that the Septal angle may also be a superior predictor of severity and RV dysfunction in patients with $\mathrm{PH}$.

PVR was critical in the assessment of CTEPH for its importance in the prediction of potential candidates for pulmonary endarterectomy and postoperative outcome (30) and NT-proBNP has been used as a noninvasive marker of the severity of right ventricular dysfunction in CTEPH (31). Although we did not analyze the threshold of the Septal angle in predicting the increased PVR and NT-proBNP in a large population, our results showed that the Septal angle strongly correlated with PVR and NT-proBNP in the CTEPH group. Jamieson et al (32) reported that patients with a preoperative PVR >1,000 (dynes.sec. $\mathrm{mm}^{-5}$ ) had a significantly higher mortality rate than those with a preoperative PVR $<1,000$ (dynes.sec.mm ${ }^{-5}$ ), so we selected 1,000 (dynes. sec. $\mathrm{mm}^{-5}$ ) as the threshold of PVR. We assessed the value of the Septal angle in predicting PVR $\geq 1,000$ (dynes.sec. $\mathrm{mm}^{-5}$ ). Using ROC curve analysis, Septal angle $>67.55^{\circ}$ demonstrated superior sensitivity and specificity with a higher AUC to identify PVR $\geq 1,000$ (dynes.sec. $\mathrm{mm}^{-5}$ ) and there was no difference in the AUC between the Septal angle and NT-proBNP level, suggesting that Septal angle and NT-proBNP have similar value in predicting a $\mathrm{PVR} \geq 1,000$ (dynes.sec. $\mathrm{mm}^{-5}$ ). These findings may be of practical importance for patients with CTEPH, CTPA not only demonstrates the distribution of clots but also supplies the information of the operability of pulmonary endarterectomy and predicts the survival of patients.

Hemodynamic data and biomarkers aid the diagnosis and assessment of PAH (33). Mukerjee et al (34) showed that NT-proBNP levels correlated significantly with PVR in scleroderma patients with PAH. Souza et al (35) showed NT-proBNP levels had a high correlation with hemodynamic parameters, particularly PVR in patients with idiopathic pulmonary artery hypertension (IPAH). Our study also showed that the Septal angle was strongly correlated with CO, PVR and NT-proBNP 
in PAH patients, suggesting that the severity of PAH or right heart strain as measured by hemodynamic data may be estimated using the Septal angle. However, further observation is required due to the relatively small number in this group. Fijalkowska et al (6) demonstrated that a NT-proBNP cut-off point at $\geq 1,400 \mathrm{pg} / \mathrm{ml}$ was useful in identifying $\mathrm{PH}$ patients with poor long-term prognosis. Notably, using ROC analysis, we observed a serum NT-proBNP level of $\geq 1,433 \mathrm{pg} / \mathrm{ml}$ has a similar value to a Septal angle of $\geq 67.5^{\circ}$ for predicting the PVR $\geq 1,000$ (dynes.sec. $\mathrm{mm}^{-5}$ ) in PH and CTEPH patients, suggesting the predictive value of a Septal angle $\geq 67.5^{\circ}$ may also be used to evaluate the long-term prognosis in $\mathrm{PH}$ patients.

Although the present observations indicate that the CTPA-derived Septal angle is a useful parameter for evaluating the severity and RV dysfunction in $\mathrm{PH}$, there are possible limitations. First, the retrospective design of our study allows for less generalization from our results, so although the Septal angle correlated with PVR and NT-proBNP, the correlations require further verification by prospective observations. Secondly, although the Septal angle appears to be useful in evaluating hemodynamics in patients with CTEPH, it is unclear whether operability and surgical success, defined as mortality and/or improvement of PVR, may be predicted with sufficient accuracy since only 14 patients underwent PEA. Our observations require verification from future studies of larger numbers of patients to determine the usefulness of preoperative CTPA in identifying RV dysfunction in high-risk CTEPH patients and the association with postoperative hemodynamic outcome, RV failure and mortality. Thirdly, the Septal angle appears to be useful in evaluating the severity of $\mathrm{PH}$ and a Septal angle $\geq 67.5^{\circ}$ also may be used to evaluate the long-term prognosis. However, the lack of prognostic data in a follow-up period may be considered a major limitation of this study. The cut-off value of septal angle is able to indicate the right ventricular function and may assess the prognosis of patients with pulmonary hypertension. However, this would require a larger and homogeneous cohort, considering the numerous therapeutic options available at present.

In summary, our results suggest that the measurement of the Septal angle by CPTA is simple, noninvasive and may be a useful parameter to assess the severity and RV dysfunction in $\mathrm{PH}$ and its two subgroups.

\section{Acknowledgements}

The authors thank Dr Renyou Zhai for helpful comments regarding hemodynamics and Dr Xiaoxia Peng for advice on data management and for valuable suggestions about statistical analysis. This study is supported by the Beijing Clinical Medical Research Foundation (Z121107001012126).

\section{References}

1. McLaughlin VV, Archer SL, Badesch DB, et al: ACCF/AHA 2009 expert consensus document on pulmonary hypertension: a report of the American College of Cardiology Foundation Task Force on Expert Consensus Documents and the American Heart Association developed in collaboration with the American College of Chest Physicians; American Thoracic Society, Inc.; and the Pulmonary Hypertension Association. J Am Coll Cardiol 53: 1573-1619, 2009.
2. Galiè N, Hoeper MM, Humbert M, et al; ESC Committee for Practice Guidelines (CPG): Guidelines for the diagnosis and treatment of pulmonary hypertension: the Task Force for the Diagnosis and Treatment of Pulmonary Hypertension of the European Society of Cardiology (ESC) and the European Respiratory Society (ERS), endorsed by the International Society of Heart and Lung Transplantation (ISHLT). Eur Heart J 30: 2493-2537, 2009.

3. Guillinta P, Peterson KL and Ben-Yehuda O: Cardiac catheterization techniques in pulmonary hypertension. Cardiol Clin 22: 401-415, 2004.

4. Seino Y, Ogawa A, Yamashita T, et al: Application of NT-proBNP and BNP measurements in cardiac care: a more discerning marker for the detection and evaluation of heart failure. Eur $\mathbf{J}$ Heart Fail 6: 295-300, 2004.

5. Pruszczyk P: N-terminal pro-brain natriuretic peptide as an indicator of right ventricular dysfunction. J Card Fail 11 (5 Suppl): S65-S69, 2005.

6. Fijalkowska A, Kurzyna M, Torbicki A, et al: Serum N-terminal brain natriuretic peptide as a prognostic parameter in patients with pulmonary hypertension. Chest 129: 1313-1321, 2006.

7. Casserly B and Klinger JR: Brain natriuretic peptide in pulmonary arterial hypertension: biomarker and potential therapeutic agent. Drug Des Devel Ther 29: 269-287, 2009.

8. Hoey ET, Gopalan D, Agrawal SK and Screaton NJ: Cardiac causes of pulmonary arterial hypertension: assessment with multidetector CT. Eur Radiol 19: 2557-2568, 2009.

9. Ghuysen A, Ghaye B, Willems V, et al: Computed tomographic pulmonary angiography and prognostic significance in patients with acute pulmonary embolism. Thorax 60: 956-961, 2005.

10. Collomb D, Paramelle PJ, Calaque O, et al: Severity assessment of acute pulmonary embolism: evaluation using helical CT. Eur Radiol 13: 1508-1514, 2003.

11. Nural MS, Elmali M, Findik S, et al: Computed tomographic pulmonary angiography in the assessment of severity of acute pulmonary embolism and right ventricular dysfunction. Acta Radiol 50: 629-637, 2009.

12. Johnson TR, Nikolaou K, Becker A, Leber AW, Rist C, Wintersperger BJ, Reiser MF and Becker CR: Dual-source CT for chest pain assessment. Eur Radiol 18: 773-780, 2008.

13. Revel MP, Faivre JB, Remy-Jardin M, Delannoy-Deken V, Duhamel A and Remy J: Pulmonary hypertension: ECG-gated 64-section CT angiographic evaluation of new functional parameters as diagnostic criteria. Radiology 250: 558-566, 2009.

14. Doğan H, Kroft LJ,Huisman MV, van der Geest RJ and de Roos A: Right ventricular function in patients with acute pulmonary embolism: analysis with electrocardiography-synchronized multi-detector row CT. Radiology 242: 78-84, 2007.

15. Liu M, Ma Z, Guo X, Zhang H, Yang Y and Wang C: Computed tomographic pulmonary angiography in the assessment of severity of chronic thromboembolic pulmonary hypertension and right ventricular dysfunction. Eur J Radiol 80: e462-e469, 2011.

16. Liu M, Ma ZH, Guo XJ, et al: A septal angle measured on computed tomographic pulmonary angiography can noninvasively estimate pulmonary vascular resistance in patients with chronic thromboembolic pulmonary hypertension. J Thorac Imaging 27: 325-330, 2012.

17. Liu M,MaZ, Guo X, Chen X, Yang Y and Wang C: Cardiovascular parameters of computed tomographic pulmonary angiography to assess pulmonary vascular resistance in patients with chronic thromboembolic pulmonary hypertension. Int J Cardiol 164: 295-300, 2013

18. Tramarin R, Torbicki A, Marchandise B, Laaban JP and Morpurgo M; Working Group on Noninvasive Evaluation of Pulmonary Artery Pressure. European Office of the World Health Organization, Copenhagen: Doppler echocardiographic evaluation of pulmonary artery pressure in chronic obstructive pulmonary disease. A European multicentre study. Eur Heart J 12: 103-111, 1991.

19. Ganz W, Donoso R, Marcus HS, Forrester JS and Swan HJ: A new technique for measurement of cardiac output by thermodilution in man. Am J Cardiol 27: 392-396, 1971.

20. McMichael J and Sharpey-Schafer EP: Cardiac output in man by a direct fick method: Effects of posture, venous pressure change, atropine, and adrenaline. Br Heart J 6: 33-40, 1944.

21. Bogaard HJ, Abe K, Vonk Noordegraaf A and Voelkel NF: The right ventricle under pressure: cellular and molecular mechanisms of right-heart failure in pulmonary hypertension. Chest 135: 794-804, 2009. 
22. Delcroix M, Vonk Noordegraaf A, Fadel E, Lang I, Simonneau G and Naeije R: Vascular and right ventricular remodelling in chronic thromboembolic pulmonary hypertension. Eur Respir J 41: 224-232, 2013.

23. Sitbon O, Humbert M, Nunes $\mathrm{H}$, et al: Long-term intravenous epoprostenol infusion in primary pulmonary hypertension: prognostic factors and survival. J Am Coll Cardiol 40: 780-788, 2002.

24. Raymond RJ, Hinderliter AL, Willis PW, Ralph D, et al: Echocardiographic predictors of adverse outcomes in primary pulmonary hypertension. J Am Coll Cardiol 39: 1214-1219, 2002.

25. McGoon M, Gutterman D, Steen V, Barst R, et al: Screening, early detection, and diagnosis of pulmonary arterial hypertension: ACCP evidence based clinical practice guidelines. Chest 126 (1 Suppl): 14S-34S, 2004.

26. Andreassen AK, Wergeland R, Simonsen S, Geiran O, Guevara C and Ueland T: N-terminal pro-B-type natriuretic peptide as an indicator of disease severity in a heterogeneous group of patients with chronic precapillary pulmonary hypertension. Am J Cardiol 98: 525-529, 2006.

27. Nagaya N, Nishikimi T, Okano Y, et al: Plasma brain natriuretic peptide levels increase in proportion to the extent of right ventricular dysfunction in pulmonary hypertension. J Am Coll Cardiol 31: 202-208, 1998

28. McDonagh TA, Holmer S, Raymond I, Luchner A, Hildebrant P and Dargie HJ: NT-proBNP and the diagnosis of heart failure: a pooled analysis of three European epidemiological studies. Eur J Heart Fail 6: 269-273, 2004.
29. Yap LB, Ashrafian H, Mukerjee D, Coghlan JG and Timms PM: The natriuretic peptides and their role in disorders of right heart dysfunction and pulmonary hypertension. Clin Biochem 37: 847-856, 2004

30. D'Armini AM, Cattadori B, Monterosso C, et al: Pulmonary thromboendarterectomy in patients with chronic thromboembolic pulmonary hypertension: hemodynamic characteristics and changes. Eur J Cardiothorac Surg 18: 696-702, 2000.

31. Reesink HJ, Tulevski II, Marcus JT, Boomsma F, et al: Brain natriuretic peptide as noninvasive marker of the severity of right ventricular dysfunction in chronic thromboembolic pulmonary hypertension. Ann Thorac Surg 84: 537-543, 2007.

32. Jamieson SW, Kapelanski DP, Sakakibara N, et al: Pulmonary endarterectomy: experience and lessons learned in 1,500 cases. Ann Thorac Surg 76: 1457-1464, 2003.

33. Badesch DB, Champion HC, Sanchez MA, et al: Diagnosis and assessment of pulmonary arterial hypertension. J Am Coll Cardiol 54 (1 Suppl): S55-S66, 2009.

34. Mukerjee D, Yap LB, Holmes AM, Nair D, et al: Significance of plasma N-terminal pro-brain natriuretic peptide in patients with systemic sclerosis-related pulmonary arterial hypertension. Respir Med 97: 1230-1236, 2003.

35. Souza R, Jardim C, Julio Cesar Fernandes C, Silveira Lapa M, et al: NT-proBNP as a tool to stratify disease severity in pulmonary arterial hypertension. Respir Med 101: 69-75, 2007. 